\title{
Antimicrobial resistance and related issues: An overview of Bangladesh situation
}

\author{
Md. Sayedur Rahman and Sharmila Huda
}

Department of Pharmacology, Bangabandhu Sheikh Mujib Medical University, Shahbag, Dhaka, Bangladesh.

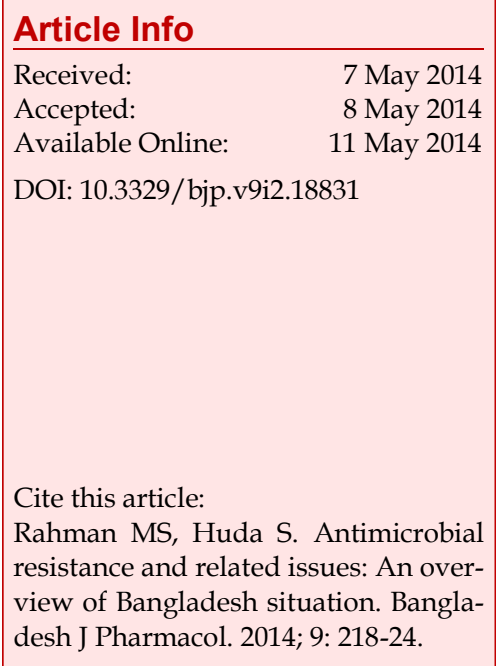

\section{Abstract}

The present study was designed to understand Bangladesh situation about antimicrobial resistance. Half of the Escherichia coli, Staphylococcus aureus, Pseudomonas and Klebsiella showed resistance against older and common antimicrobials. Most $(50 \%)$ common reasons to prescribe antimicrobial are fever, respiratory and urinary tract infection. About $70 \%$ prescriber mentioned diagnostic uncertainty and emergence of resistance as causes for increase in antimicrobial prescribing. $51.9 \%$ of prescribers opined that physicians prescribe antimicrobial more than the actual need. About twothird of $5^{\text {th }}$ year medical students answered correctly on different issues related to antimicrobials and resistance. Antimicrobial and resistance received little emphasis in Pharmacology and Microbiology written questions at both undergraduate $(0.7$ to $16.1 \%)$ and postgraduate (0.9 to $18.4 \%)$ level. Print $(0.02$ to $2.0 \%)$ and electronic media (0.0 to $0.6 \%)$ attaches small importance on the issues. Nothing related to 'antimicrobials' and 'measure to contain resistance' were mentioned in related policy documents.

\section{Introduction}

Different studies conducted in Bangladesh during last decade revealed that there is polypharmacy, high use of antimicrobials, vitamins and injectables in hospitals and very low generic prescribing (Rahman et al., 1998; Islam et al., 2007; Chowdhury et al., 2008; Das and Rahman, 2010; Holloway, 2010). Moreover, inadequate access to effective antimicrobials, incomplete therapy and though occasional but questionable quality of medicine negatively contributed in emergence of resistance (Okeke et al., 1999; WHO, 2000; Faiz and Basher, 2011). Antimicro -bial resistance is a mounting threat to the control of infectious diseases both globally as well as locally in Bangladesh. During last seventy years, development of effective antimicrobials had reduced incidence of lifethreatening infections, however that achievement has been eroded by the emergence of resistance (Shnayerson and Plotkin, 2002). Microbes developed resistance primarily in the hospitals, however that later spread in the community imposing more risk to the human health. Infections with resistant microbes not only result in greater morbidity and mortality, but also increase the health care costs. The loss of effectiveness of the antimicrobials leads to longer duration of research as well as increased development expenses (Levy, 2002).

Against this background, attempt has been taken, to overview the status of antimicrobial resistance and related contributory issues in Bangladesh. Evidences were gathered on sensitivity pattern, emphasis on antimicrobial related issues in teaching-learning activities in medical and general education, emphasis on related issues in electronic and print media, understanding of the medical students on related issues and perception of prescribers regarding antimicrobial prescribing. Moreover, to obtain a detail picture, medicine related policies and regulations were analyzed. 


\section{Materials and Methods \\ Sensitivity pattern of the microbes isolated in different institutions}

Information on antimicrobial sensitivity pattern of Escherichia coli, Staphylococcus aureus, Pseudo-monas and Klebsiella isolated in the Department of Microbiology of Bangabandhu Sheikh Mujib Medical University (BSMMU), Bangladesh Medical College, Ibrahim Medical College and Rajshahi Medical College during the period from July 2010 to December 2010 was collected from the departmental records. The collected data were cleaned, synchronized and compiled in a common table, which was analyzed later.

\section{Understanding of medical community on antimicrobial resistance}

\section{Study among physicians}

Questionnaire survey was conducted among physicians of different institutions during March 2011 on clinical conditions leading to antimicrobial prescribing, perceived factors that increase antimicrobials prescribing and opinion regarding statement "physicians prescribe antimicrobial more than they actually need".

\section{Study among $5^{\text {th }}$ year medical students}

Questionnaire survey was conducted among $5^{\text {th }}$ year medical students of different medical colleges during March 2011 regarding different aspects on antimicrobial related issues. A questionnaire was prepared on 'antimicrobial spectrum', 'clinical use', 'theory on resistance'. The respondents were asked about the diseases for which they have taken antimicrobials and the name of the antimicrobial taken in last six months. In addition, whether the antimicrobials were taken according to qualified physicians or not were enquired and in case of positive response, the respondents were asked about whether the course was completed or not.

Emphasis on antimicrobial resistance in teaching-
learning activities of medical institutions Undergraduate: All available questions on Pharmacology and Microbiology of 2nd Professional MBBS examinations held between January 2006 and July 2010 in all universities of Bangladesh were included. Questions on 'antimicrobial' and 'resistance' were identified and labeled by the qualified pharmacologists on the principle of conceptual mapping. Marks allocated for the designated question was then recorded. Proportion of marks allocated was calculated on the basis of total marks mentioned in the questions.

Postgraduate: All available questions on Pharmacology and Microbiology for MD and MS examinations of different disciplines held in all universities of Bangladesh (January 2006 to July 2010) were included. Questions on 'antimicrobial' and 'resistance' were identified and labeled by the qualified pharmacologists on the principle of conceptual mapping. Marks allocated for the designated question was then recorded. Proportion of marks allocated was calculated on the basis of total marks mentioned in the questions.

Emphasis on antimicrobial resistance in general education

Textbooks on science and related disciplines of class VI to class XII were analyzed using conceptual mapping in order to calculate the emphasis on 'health', 'drug', 'antimicrobials' /'antibiotics', 'resistance'. Similarly, Biology questions papers of the Secondary School Certificate (SSC) examinations held from 2006 to 2010, Botany and Zoology question papers of the Higher Secondary Certificate (HSC) examinations held from 2006 to 2010 were also analyzed.

\section{Emphasis on antimicrobial resistance in print media}

Four daily newspapers were selected [two Bengali and two English] and they were collected for the month of March 2011. The total area of the newspapers was measured in sq inch including the news, features, magazines and advertisements. The news or features were categorized and labeled into 'health', 'drug', 'antibiotic' and 'resistance', which were measured in sq inch to be expressed as percentage of the total area of the newspaper.

\section{Emphasis on antimicrobial resistance in electronic media}

Three television channels [Channel I, Banglavision and Ekushey Television] were selected for the study. The 'health', 'drug', 'antibiotic' and 'resistance' related news or features were calculated in hours to be expressed as percentage of the total hour broadcasted.

\section{Policy analysis}

'National Health Policy 2010', 'National Drug Policy 2005', 'Drug (Control) Ordinance 1982', 'Bengal Drug Rules 1946' and 'Bengal Drug Act 1940', were collected (either hard copy or electronic version). These documents were searched by key words 'antibiotic', 'antimicrobials', 'rational', 'dispensing', 'prescribing', 'resistance', 'over the counter'. If the searched word was present, it was marked manually.

The methodology of studies and tools of data collection was validated. The data on different issues related to antimicrobial resistance at different levels were assessed. Input were received from the related experts, particularly regarding methodology was appreciated.

\section{Results}

The sensitivity pattern of E. coli shows that this microbe is about $40 \%$ sensitive to ciprofloxacin, ceftazidime, 


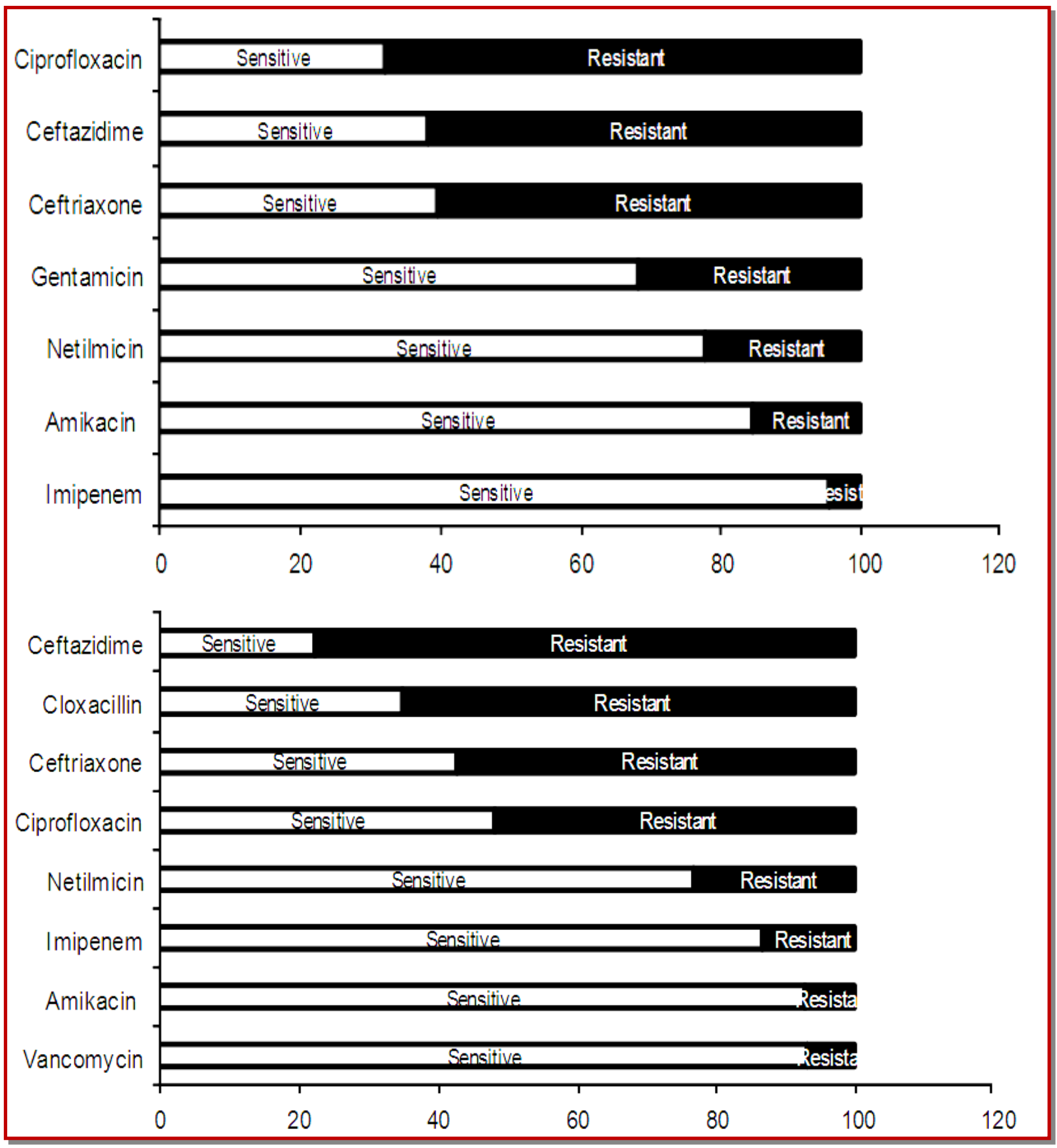

Figure 1: Antimicrobial sensitivity pattern of E. coli $(\mathrm{n}=1293$; Upper), S. aureus $(\mathrm{n}=114$; Lower)

ceftriaxone and about $90 \%$ sensitive to amikacin and imipenam (Figure 1). The results of $S$. aureus shows that, they are about $30 \%$ sensitive to ceftazidime, about $40 \%$ sensitive to cloxacillin, ceftriaxone and about $95 \%$ sensitive to amikacin and vancomycin (Figure 1). The sensitivity pattern of Pseudomonas reveals that they are almost $30 \%$ sensitive to ceftazidime and ceftriaxone, about $50 \%$ sensitive to netilmicin, ciprofloxacin and almost 95\% sensitive to imipenam (Figure 2). The sensitivity picture of Klebsiella is about $40 \%$ sensitive to ceftriaxone, ciprofloxacin, $80 \%$ to amikacin, imipenam and almost 95\% sensitive to azithromycin (Figure 2).

According to the physicians of different institutions, most of them (about 50\%) prescribe antimicrobials in respiratory tract infection, fever and urinary tract infection. Few (about 10\%) prescribe in otitis media, dysentery, septicemia (Table I). Majority of them (about $70 \%$ ) pointed out that diagnostic uncertainty and emergence of resistant microbes are the main causes for increase in antimicrobial prescribing. It is also mentionable that $16.4 \%$ of them prescribe antimicrobials as 


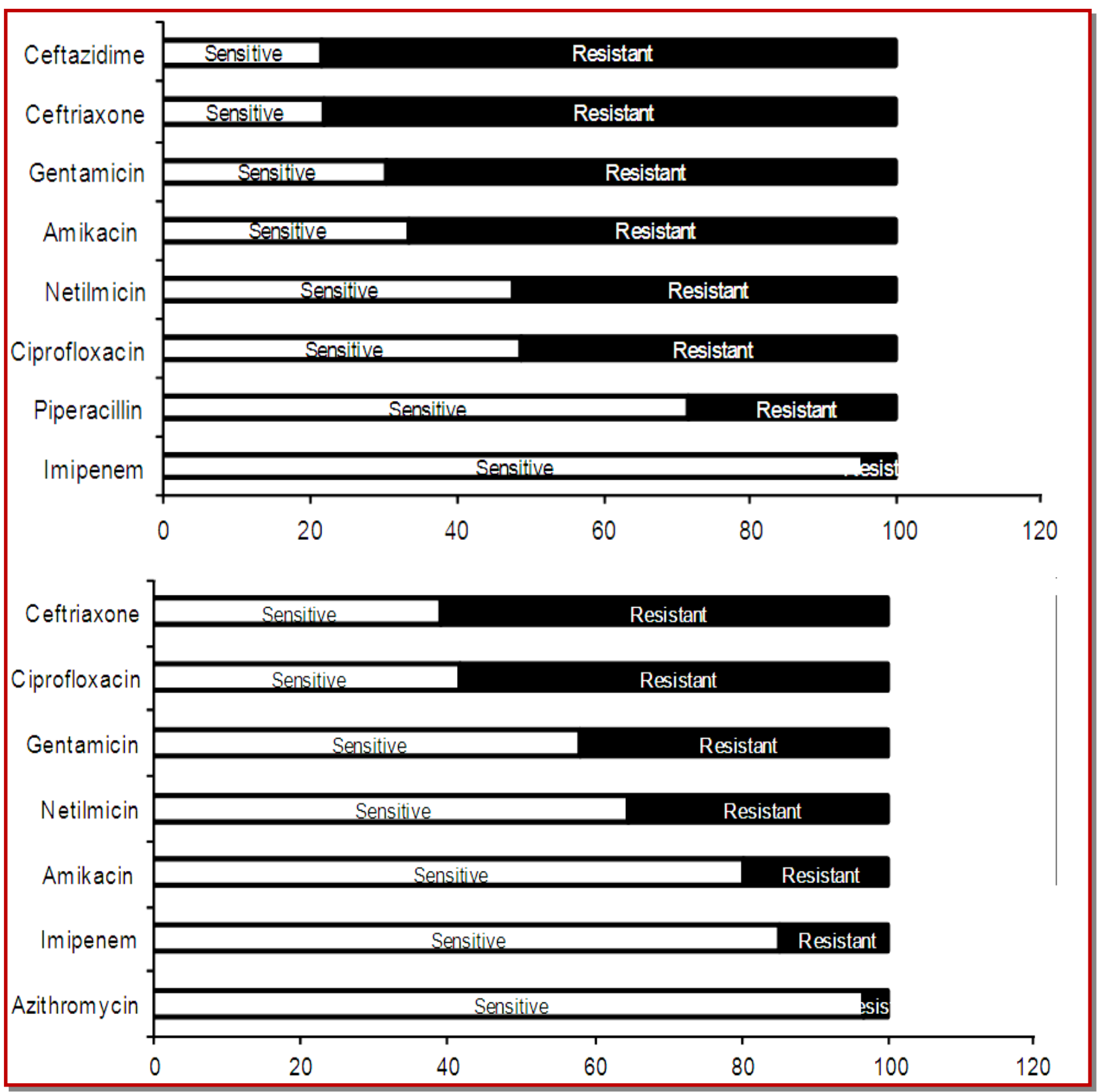

Figure 2: Antimicrobial sensitivity pattern of Pseudomonas ( $\mathrm{n}=225$; Upper), and Klebsiella ( $\mathrm{n}=171$; Lower)

there is possibility of losing patient (Table II). Over all $51.9 \%$ physicians agreed with the statement, "Physicians prescribe antimicrobial more than they actually need"; whereas $24.8 \%$ disagreed with the statement.

In survey conducted on $5^{\text {th }}$ year medical students, about $71.3 \%$ of them answered correctly on clinical use of antimicrobials, 67.3 and $57.9 \%$ answered correctly about 'theory on resistance' and 'antimicrobial spectrum' respectively. While enquired about reason of taking antimicrobials in last 6 months, 23.8, 24.8, 23.9 and $12.1 \%$ of the students mentioned fever, sore throat, diarrhea and RTI respectively as their reason. Due to these reasons, the students had taken different antimicrobials like- azithromycin (67\%), ciprofloxacin
$(48 \%)$, amoxicillin $(30 \%)$, metronidazole $(25 \%)$, cefradine (20\%), flucloxacin (10\%) and others (31\%).

Among the students, $76.0 \%$ took antimicrobials according to prescription of qualified physicians, $15.7 \%$ took antimicrobials not prescribed by physicians and 6.4 were not sure about the issue. The students who took antimicrobials as prescribed by qualified physicians, $80.2 \%$ completed the course, and the remaining (19.8\%) stopped taking the antimicrobial before completion of course.

The emphasis on antimicrobial and resistance in written questions of Pharmacology and Microbiology of MBBS examinations were evaluated. It was revealed that, in Pharmacology 16.1 and $0.8 \%$ questions covered anti- 


\begin{tabular}{|lc|}
\hline \multicolumn{2}{|c|}{ Table I } \\
\hline \multicolumn{2}{|c|}{$\begin{array}{c}\text { Common conditions for which graduate } \\
\text { physicians prescribe antimicrobials }\end{array}$} \\
\hline Clinical condition & $\begin{array}{c}\text { Proportion of physicians } \\
\text { mentioned }(\mathrm{n}=214)\end{array}$ \\
\hline Respiratory tract infection & $57.9(124 / 214)$ \\
Fever & $54.2(116 / 214)$ \\
Urinary tract infection & $50.9(109 / 214)$ \\
Postoperative infection & $36.9(79 / 214)$ \\
Meningitis & $32.2(69 / 214)$ \\
Diarrhea & $12.2(26 / 214)$ \\
Otitis media & $11.7(25 / 214)$ \\
Dysentery & $11.7(25 / 214)$ \\
Speticemia & $11.7(25 / 214)$ \\
Sore throat & $5.1(11 / 214)$ \\
Others & $88.3(189 / 214)$ \\
\hline
\end{tabular}

microbial and resistance respectively, whereas in Microbiology 1.6 and $0.7 \%$ questions covered antimicrobial and resistance respectively.

The emphasis on antimicrobial and resistance in written questions of Pharmacology and Microbiology of MS and MD examinations were evaluated. In Pharmacology compartment of different MS examinations, $18.4 \%$ questions were on antimicrobial and $1.2 \%$ on resistance. In different MD examinations, $13.3 \%$ questions were on antimicrobials and $1.2 \%$ on resistance. In Microbiology compartment of different MS examinations, the scenario is, $1.4 \%$ questions were on antimicrobial and $2.1 \%$ on resistance. In different MD examinations, $0.9 \%$ questions were on antimicrobials and $0.9 \%$ on resistance.

In general education, emphasis on health awareness, microbes, antimicrobial and resistance in books from class VI to class XII had ranged between 11 to $69 \%$ on health awareness and 7 to $38 \%$ on microbes. However, there is no $(0 \%)$ coverage on antimicrobial and resistance. In Botany and Zoology questions papers of SSC and HSC examinations, 10.3 to $17.3 \%$ questions cover microbes, 0.9 to $2.5 \%$ on antimicrobials and no questions on resistance.

In print media, coverage of health, drug, antimicrobial and resistance in newspaper shows that, 0.5 to $2.0 \%$ area covers health related features and news; out of which, 0.0 to $0.5 \%$ covers drug related features and news. There was no coverage in features and news on antimicrobial and resistance related issues.

In electronic media, 0.4 to $0.6 \%$ time of the total duration of program was on health related issues, 0 to $0.02 \%$ of total time duration was on drug related programs. Only one channel broadcasted a program on antimicrobial and resistance for one hour, which covered $0.01 \%$ hour of the total time of broadcasting.

\begin{tabular}{|c|c|}
\hline \multicolumn{2}{|l|}{ Table II } \\
\hline \multicolumn{2}{|c|}{$\begin{array}{l}\text { Factors identified by physicians that increase } \\
\text { anti-microbials prescribing }\end{array}$} \\
\hline Factors & $\begin{array}{l}\text { Proportion of physi- } \\
\text { cians mentioned } \\
(\mathrm{n}=214)\end{array}$ \\
\hline Diagnostic uncertainty & $73.8(158 / 214)$ \\
\hline Emergence of resistant microbes & $72.0(154 / 214)$ \\
\hline Earlier treatment by quack & $52.3(112 / 214)$ \\
\hline $\begin{array}{l}\text { Lack of information about sensitivi- } \\
\text { ty pattern }\end{array}$ & $49.1(105 / 214)$ \\
\hline $\begin{array}{l}\text { Concern about cost of sensitivity } \\
\text { testing }\end{array}$ & $48.1(103 / 214)$ \\
\hline $\begin{array}{l}\text { Patient request/expectation/ } \\
\text { satisfaction }\end{array}$ & $34.6(74 / 214)$ \\
\hline Time constraint & $30.4(65 / 214)$ \\
\hline Promotion of newer antimicrobials & $21.5(46 / 214)$ \\
\hline Concern about cost of return visit & $20.1(43 / 214)$ \\
\hline Possibility of losing patient & $16.4(35 / 214)$ \\
\hline
\end{tabular}

In the studied policy documents on health and medicine, nothing related to 'antimicrobials' and 'measure to contain resistance' were mentioned.

\section{Discussion}

The link between inappropriate use of antimicrobials and development of antimicrobial resistance was acknowledged in different scientific studies and global proceedings (WHO, 1998; 2002). In Bangladesh, prescribers generally diagnose microbial infection on clinical judgment and select antimicrobial on empirical basis (Faiz and Rahman, 2004), which unfavorably affected the sensitivity pattern of microbes. Moreover, reluctance of the lawmakers and regulators to enact law to overcome inadequacy in rules and regulation to control antimicrobial prescribing and dispensing led to worsening of the situation.

Antimicrobial sensitivity pattern reflects the emergence of resistance against common antimicrobials, which are similar with that of the previous studies (Okeke et al., 2005; Rahman et al., 2007; Akond et al., 2009; Rogers et al., 2011). Though antimicrobials like ciprofloxacin, ceftazidim and ceftriaxone have become ineffective because of emergence of resistance, the microbes are still sensitive to imipenam, azitrhomycin, vancomycin and amikacin. This pattern of sensitivity does not correlate with the previous findings (Hasan et al., 2011). Prescribers mentioned diagnostic uncertainty and emergence of resistance as major causes of prescribing antimicrobials, though some of them mentioned possibility of losing patients as one reason.

Antimicrobial and resistance received very little importance at the undergraduate level (MBBS) in the course 
and examinations of Pharmacology and Microbiology subject. Whereas, at postgraduate level, portion of the MD and MS postgraduate curricula also represent similar picture. The emphasis on antimicrobials was similar in the previous study conducted at undergraduate level (Begum et al., 1999). Medical education of Bangladesh was not adequately addressing the impending health issues of the country, which was discussed earlier and some changes were suggested (Rahman, 1995a; Rahman, 1995b). There was innovative effort to improve the relevance of the course content and required prescribing skill of the future medical graduates (Rahman et al., 2000). Recent undergraduate medical curriculum (BMDC, 2012) has incorporated some of the recommendations of previous studies, which might contribute positively in near future.

In case of general education, microbes are taught at SSC and HSC levels in Botany and Zoology subjects. Though, antimicrobials and resistance are not receiving any importance, which should be taught and evaluated in the SSC and HSC levels under any relevant subject. People become aware about different issues through learning from different sources including lay media. The antimicrobial related issues received negligible emphasis in different print and electronic media, indicating little awareness among the key anchors of health programs and news editors of health pages regarding antimicrobials related issues and it's implications.

Inadequate information was available about these issues beforehand in Bangladesh. Through this study, a quick overview of the situation was done and a number of evidences on status of the issue in different spheres of life were gathered. In addition, comprehensive information was obtained on sensitivity pattern of microbes, emphasis of antimicrobial resistance in different teaching-learning activities, print and electronic media. In spite of having an excellent National Drug Policy formulated in 1982, which was updated later in 2005, nothing was mentioned as directives and regulation in any of the antimicrobial related policy documents. The clarity of understanding about the status of antimicrobial resistance and the perceived influencing factors is essential to take initiative to contain emergence of resistance. The findings of the present study will form the conceptual basis of initiatives directed towards containing emergence of bacterial resistance.

"War is too important to be left to the generals," as paraphrased in Clemenceau and the Third Republic (Jackson, 1946). The struggle of human to conserve the effectiveness of antimicrobials against microbes is so complicated that require concerted effort of number of experts. In this context, war against microbes is too important to be left to the clinicians. There are too many aspects of infection management that are out of the scope and training of the clinician. Therefore, pharmacologists, microbiologists, epidemiologists and molecu- lar biologists all must participate in a concerted effort to design sound strategies to contain antimicrobial resistance by using antimicrobials scientifically to manage infectious diseases. The present study was just a preliminary and quick assessment, which formed the foundation of future researches.

\section{Acknowledgement}

The principal author gratefully acknowledges the financial support received from World Health Organization on the eve of World Health Day 2011 to conduct the study. The author also likes to express gratitude to the teachers of the participating departments of different institutions for their generous support and help and especially to the students of the Department of Pharmacology, BSMMU who worked hard for the study.

\section{References}

Akond MA, Alam S, Hassan SMR, Shirin M. Antibiotic resistance of Escherichia Coli isolated from poultry and poultry environment of Bangladesh. Int J Food Safety. 2009; 11: 19-23.

Bangladesh Medical \& Dental Council (BMDC). Curriculum for Undergraduate Medical Education in BangladeshUpdated 2012. Dhaka 1000, Bangladesh, 2012, pp 1-393. Available at www.bmdc.org.bd

Begum M, Rahman MS, Islam AFMS, Khan IA, Akhter N. Eleven years of the undergraduate medical curriculum 1988: Review on the changes in Pharmacology written questions. Bangladesh J Physiol Pharmacol. 1999; 15: 27-30.

Chowdhury AK, Rahman MS, Faroque AB, Hasan GA, Raihan SZ. Excessive use of avoidable therapeutic injections in the Upazilla health complexes of Bangladesh. Mymensingh Med J. 2008; 17(2 Suppl): S59-64.

Das AK, Rahman MS. Prescribing vitamins at primary health care level: Exploration of facts, factors and solution. Bangladesh J Pharmacol. 2010; 5: 92-97.

Faiz MA, Basher A. Antimicrobial resistance: Bangladesh experience. Regional Health Forum. 2011; 15: 1-8.

Faiz MA, Rahman MR. Rational antimicrobial use. J CMCTA. 2004; 15: 1-3.

Hasan B, Nahar SG, Akter L, Saleh A. Antimicrobial sensitivity pattern of Salmonella typhi isolated from blood culture in a referral hospital. Bangladesh J Med Microbiol. 2011; 05: 1620.

Holloway KA. Bangladesh: Pharmaceuticals in health care delivery. Mission Report. New Delhi, World Health Organization, Regional Office for South East Asia, 2010, pp 17-24.

Islam MS, Rahman MS, Misbahuddin M. Impact of 'Prescription Audit \& Feedback' on pattern of prophylactic antimicrobials in caesarean section: A cost reduction perspective. Bangladesh J Physiol Pharmacol. 2007; 23: 1-9.

Jackson JH. Clemenceau and the third Republic. London, Hodder \& Stoughton for the English Universities Press, 
1946, p 228.

Levy SB. The antibiotic paradox. 2nd ed. Cambridge, USA, Perseus Publlishing, 2002.

Okeke IN, Lamikanra A, Edelman R. Socioeconomic and behavioral factors leading to acquired bacterial resistance to antibiotics in developing countries. Emerg Infect Dis. 1999; 5: 18-27.

Okeke IN, Laxminarayan R, Bhutto ZA, Duse AG, Jenkins P, O'Brian TF, Pablos-Mendez A, Klugman KP. Antimicrobial resistance in developing countries. Part I: Recent trends and current status. Lancet Infect Dis. 2005; 5: 481-93.

Rahman M, Shoma S, Rashid H, Arifeen SE, Baqui AH, Siddique AK, Nair GB, Sack DA. Increasing spectrum in antimicrobial resistance of Shigella isolates in Bangladesh: Resistance to azithromycin and ceftriaxone and decreased susceptibility to ciprofloxacin. J Health Popul Nutr. 2007; 25: 158-67.

Rahman MS, Kamal ASMA, Chwodhury S, Khan IA, Islam AMZ, Sultana R, Begum M, Akhter N, Anwar AKMN. Exercise on selection of P-drug: Preliminary evaluation of a newer method of Pharmacotherepy teaching in Bangladesh. Bangladesh J Physiol Pharmacol. 2000; 16: 50-54.

Rahman MS, Khan IA, Chowdhury S, Islam AMZ, Sultana R, Hoque MZ, Akhter N. A baseline survey on the use of drugs at private practitioner level in Bangladesh. Bangladesh J Physiol Pharmacol. 1998; 14: 47-50.
Rahman MS. Changes required in pharmacotherapy teaching to ensure rational use of drugs. Bangladesh J Physiol Pharmacol. 1995; 11: 38-39.

Rahman MS. Health Care Reform, A global phenomenon: Can Bangladesh respond properly? Bangladesh Med J. 1995; 24: 28-30.

Rahman MS. New global situation in drug regulation: Redefined responsibility of the Pharmacologists of Bangladesh. Bangladesh J Physiol Pharmacol. 1999; 15: 4142 .

Rogers BA, Aminzadeh Z, Hayashi Y, Peterson DL. Country-to -Country transfer of patients and the risk of multi-resistant bacterial infections. Clin Infect Dis. 2011; 53: 49-56.

Shnayerson M, Plotkin MJ. The killers within the deadly rise of drug-resistant bacteria. New York, USA, Little Brown \& Company, 2002.

World Health Organization (WHO). Fifty first World Health Assembly. WHA 51.17. Agenda item 21.3. Geneva, 1998.

World Health Organization (WHO). Implementation workshop on the WHO global strategy for containment of antimicrobial resistance. Geneva, Department of Communicable Disease Surveillance and Response, 2002.

World Health Organization. Overcoming antimicrobial resistance. Geneva, WHO, 2000. 